\title{
Epidemiology of Anemia in Older Adults
}

\author{
Kushang V. Patel, PhD, MPH ${ }^{1}$ \\ 1 Laboratory of Epidemiology, Demography, and Biometry, Intramural Research Program, National Institute \\ on Aging Bethesda, Maryland, USA
}

\begin{abstract}
Anemia is a common, multifactorial condition among older adults. The World Health Organization (WHO) definition of anemia (hemoglobin concentration $<12 \mathrm{~g} / \mathrm{dL}$ in women and $<13 \mathrm{~g} / \mathrm{dL}$ in men) is most often used in epidemiologic studies of older adults. More than $10 \%$ of community-dwelling adults age 65 years and older has WHO-defined anemia. After age 50 years, prevalence of anemia increases with advancing age and exceeds $20 \%$ in those 85 years and older. In nursing homes, anemia is present in $48-63 \%$ of residents. Incidence of anemia in older adults is not well characterized. Among older adults with anemia, approximately one-third have evidence of iron, folate, and/or vitamin $\mathrm{B}_{12}$ deficiency, another third have renal insufficiency and/or chronic inflammation, and the remaining third have anemia that is unexplained. Several studies demonstrate that anemia is associated with poorer survival in older adults. This review details the distribution and consequences of anemia in older adults and identifies future epidemiologic research needs.
\end{abstract}

Population aging is occurring worldwide with both the number and proportion of older adults increasing globally. Currently, there are nearly 500 million (7\%) adults 65 years and older in the world, but by 2030 the older population will double to 1 billion (12\%). ${ }^{1}$ Increasingly, the preponderance of older persons will reside in developing countries as fertility rates have dropped dramatically and mortality has generally decreased. For instance, there will be 370 million older adults living in China and India alone by $2030 .{ }^{1}$ However, not only is the overall population aging, but the older population itself is getting older as well. In the United States, for example, the oldest-old (adults 85 years and older) is the most rapidly growing segment of the population that will quadruple to 21 million persons by 2050; at which time 1 out of every 4 older adults is projected to be 85 years and older. ${ }^{2}$ In view of this demographic reality, better characterization of the distribution and causes of health conditions that impair function and reduce survival in older ages is imperative for developing interventions that increase active life expectancy.

Over the past decade, anemia has emerged as a risk factor that is associated with a variety of adverse outcomes in older adults, including hospitalization, disability, and mortality. ${ }^{3-9}$ Anemia is essentially a homeostatic imbalance in the blood concentration of hemoglobin whereby the production of erythrocytes is outpaced by the destruction or loss of erythrocytes. The epidemiology of anemia and aging, in general, is particularly challenging because of increased heterogeneity in the distribution of social and biological risk factors with advancing age. Given that anemia is a multifactorial condition, the increased comorbidity in older adults

Address correspondence to: Kushang V. Patel, 7201 Wisconsin Avenue, Gateway Building, Suite 3C309, Bethesda, MD 20892-9205 (Tel.: 301-496-6076; Fax: 301-496-4006; Email: patelku@ mail.nih.gov).

Publisher's Disclaimer: This is a PDF file of an unedited manuscript that has been accepted for publication. As a service to our customers we are providing this early version of the manuscript. The manuscript will undergo copyediting, typesetting, and review of the resulting proof before it is published in its final citable form. Please note that during the production process errors may be discovered which could affect the content, and all legal disclaimers that apply to the journal pertain. 
makes it difficult to establish whether anemia is a marker of disease burden or a mediator in the causal pathway leading to adverse events. This paper will review the distribution and types of anemia in older adults as well as highlight analytic challenges and identify future epidemiologic research needs.

\section{Distribution of Anemia}

\section{Prevalence by age and sex}

Estimates of anemia prevalence vary depending on the case definition applied and the demographic and health status composition of study samples. Although there is some debate on which hemoglobin thresholds should be used to define anemia in older adults, the World Health Organization (WHO) definition (hemoglobin concentration $<12 \mathrm{~g} / \mathrm{dL}$ in women and $<13 \mathrm{~g} / \mathrm{dL}$ in men) is the most frequently used in epidemiologic studies. Further, older persons with hemoglobin concentration below the WHO cutoffs are generally at increased risk of death, which is reviewed in a later section.

Table 1 lists prevalence estimates for WHO-defined anemia from large, well-characterized community-based studies of older adults. $5,7,9-13$ Prevalence of anemia ranged from $9.2 \%$ to $23.9 \%$ in men, while in women the range was $8.1-24.7 \%$. While there is considerably heterogeneity in estimates across studies, 2 conclusions can be clearly drawn from Table 1. First, anemia is common in community-dwelling older adults and, second, there are large racial differences in the prevalence of WHO-defined anemia. Rather than cataloging differences in sampling design across studies, which likely explain discrepancies in prevalence estimates, the report by Guralnik and colleagues merits our greatest attention because their estimates were based on data from the 1988-1994 Third National Health and Nutrition Examination Survey (NHANES III). ${ }^{10}$ The NHANES III is a nationally-representative study of noninstitutionalized civilian adults, specifically designed to provide prevalence information for major demographic subgroups in the United States, including the older population.

According to NHANES III, prevalence of WHO-defined anemia among community-dwelling adults age 65 years and older was $11.0 \%$ and $10.2 \%$ in men and women, respectively. ${ }^{10}$ The far majority of anemia cases were mild, with less than $1 \%$ of older community-dwelling adults having hemoglobin concentration below $10 \mathrm{~g} / \mathrm{dL}$ and less than $3 \%$ were below $11 \mathrm{~g} / \mathrm{dL}$. Figure 1 illustrates the tremendous age variation in the distribution of anemia. Prevalence in men was lowest between ages 17 and 49 years, while for women anemia was least common at ages 5064 years. Importantly, the prevalence of anemia increased as a function of age after the $5^{\text {th }}$ decade of life in both men and women; however, the age-associated increase in prevalence was more dramatic in men. At ages 75 years and older, anemia was more common in men than in women. ${ }^{10}$ This sex differential has been observed in other studies as well. ${ }^{11,13-15}$ At ages $75-84$ years, Salive et al ${ }^{13}$ and Skjelbakken et al ${ }^{15}$ estimated that $14.9-15.0 \%$ of men and 7.1-12.7\% of women had WHO-defined anemia. In the oldest-old ( 85 years and older), anemia was present in $29.6-30.7 \%$ of men and in $16.5-17.7 \%$ of women. 13,15 These estimates of anemia prevalence in advanced ages are quite similar to the estimates shown in Figure 1, indicating that anemia afflicts approximately 1 in 4 men and 1 in 5 women age 85 years and older living in the community. ${ }^{10}$

The cross-over effect whereby men are more likely than women to have anemia at older ages than at younger ages reflects the application of sex-specific criteria for defining anemia and, implicitly, sex differences in the distribution of hemoglobin concentration. The use of a lower hemoglobin threshold to define anemia in women past menopause has been questioned. ${ }^{3}$ In the case of the WHO criteria, men with 12.0-12.9 g/dL of hemoglobin are considered anemic, but women with identical hemoglobin concentration are classified as normal. However, if women with $12.0-12.9 \mathrm{~g} / \mathrm{dL}$ of hemoglobin were considered anemic, then prevalence of 
anemia in women age 65 years and older would rise to $32.5 \%$ (as shown in Figure 2). ${ }^{10}$ Further, prevalence in women ages $65-74,75-84$, and $\geq 85$ years would be $29.4 \%, 35.0 \%$, and $43.1 \%$, respectively, and the overall prevalence of anemia in community-dwelling older adults would double to $23.4 \%$ if men and women with hemoglobin $<13 \mathrm{~g} / \mathrm{dL}$ were considered anemic (author's analyses of NHANES III data). Given that there are distinct distributions of hemoglobin concentration by sex, it is unlikely that anemia occurs at the same hemoglobin threshold in men and women. More epidemiologic research is needed to define the hemoglobin thresholds below which risk of adverse outcomes is increased in older men and women.

\section{Prevalence by race/ethnicity}

In addition to sex differences in the distribution of hemoglobin, there are substantial differences by race as well. As far back as the 1930's, researchers observed that blacks have lower hemoglobin concentration than whites. ${ }^{16}$ These differences are not explained by health, nutrition, or socioeconomic status and are observed throughout the age spectrum, including in healthy children and younger adults. ${ }^{17-19}$ It is likely that gene mutations selected by different environmental pressures occurring in Africa and Europe contribute to racial differences in hemoglobin concentration. For example, $\alpha$-thalassemia and glucose-6-phosphate deficiency are red blood cell disorders known to confer survival benefits from malaria infection and are far more common in blacks than in whites. A study by Beutler and West showed that although racial differences in hemoglobin concentration narrowed after excluding African American participants with iron deficiency, $\alpha$-thalassemia, and sickle cell trait, differences in hemoglobin remained significant, indicating that other adaptive factors likely exist. ${ }^{20}$ Figure 3 illustrates that the shifted distribution of hemoglobin concentration toward lower values in older nonHispanic blacks relative to older non-Hispanic whites profoundly affects the prevalence of anemia. Indeed, it is not surprising that anemia prevalence is 2 to 3 times higher in blacks than in whites when the WHO criteria are applied (Table 1). As reported by Guralnik et al., the prevalence of WHO-defined anemia in the United States was 9.2\% and $8.7 \%$ in older nonHispanic white men and women, respectively, but in older non-Hispanic black men and women prevalence was $27.5 \%$ and $28.0 \%$, respectively. ${ }^{10}$ Importantly, the distribution of hemoglobin concentration among older Mexican Americans, a rapidly growing segment of the older US population that is similar to older non-Hispanic blacks in terms of socioeconomic disadvantage, was similar to the distribution in non-Hispanic whites (Figure 3). Prevalence of WHO-defined anemia in older Mexican American men and women was $11.5 \%$ and $9.3 \%$, respectively. ${ }^{10}$

The long observed racial differences in hemoglobin distribution have prompted some expert groups to recommend race-specific criteria for defining anemia. $18,19,21-23$ Recently, Beutler and Waalen proposed age-, sex-, and race-specific criteria by identifying the $5^{\text {th }}$ percentile value of hemoglobin concentration for each of the demographic subgroups observed in healthy participants of 2 large studies (Scripps-Kaiser, a patient database from San Diego and NHANES III). ${ }^{18}$ As expected, the hemoglobin thresholds for defining anemia were lower in older, female, and black participants. ${ }^{18}$ While it is reasonable to apply the $5^{\text {th }}$ percentile value as the lower boundary of normal after excluding sick individuals, another approach is to examine risk for adverse outcomes as a function of hemoglobin concentration. For example, in a biracial cohort study of relatively well-functioning older adults, WHO-defined anemia was a significantly strong predictor of mortality and mobility disability in white men and women, but not in black men or women. ${ }^{7}$ Although there was some evidence that the hemoglobin threshold below which mortality risk increased was lower in black men than in white men, statistical power was limited to clearly identify hemoglobin thresholds based on mortality risk.

${ }^{7}$ However, recently completed analysis of the NHANES III-mortality linked file clearly demonstrated that risk of death was significantly increased in non-Hispanic whites and Mexican Americans at hemoglobin concentrations of $0.4 \mathrm{~g} / \mathrm{dL}$ and $0.2 \mathrm{~g} / \mathrm{dL}$, respectively, above the WHO cutpoints for anemia, but in non-Hispanic blacks the hemoglobin threshold 
was $0.7 \mathrm{~g} / \mathrm{dL}$ below the WHO cutpoints (Patel et al., original paper under review). The magnitude of difference by race/ethnicity in the distribution of hemoglobin (mean difference of $1.0 \mathrm{~g} / \mathrm{dL}$ between non-Hispanic blacks and whites) was very similar to differences in hemoglobin thresholds for increased mortality risk. In addition, this study further showed that all of the major subtypes of anemia were associated with increased mortality and therefore differences in the causes of anemia are unlikely to account for racial/ethnic variation in the risk of death according to hemoglobin concentration (Patel et al., original paper under review). These prospective studies along with numerous cross-sectional studies reporting racial differences in hemoglobin concentration suggest that race-specific criteria for defining anemia should be considered, but further outcomes-based research in racially/ethnically diverse community-based studies would help to define clinically-relevant hemoglobin cutpoints.

\section{Prevalence in nursing homes}

While community-based, representative studies are critical to understanding the distribution and burden of anemia in the older population, it is also important to recognize that anemia is even more common in institutional settings. Although there are no published national estimates of anemia prevalence in nursing home facilities, a few studies have retrospectively reviewed the records of nursing home residents to estimate the prevalence of WHO-defined anemia. For instance, Artz and colleagues examined the charts of 900 residents in 5 skilled-nursing homes and reported that $48 \%$ of residents had anemia. ${ }^{24}$ Among anemic nursing home residents in the study, 30\% had been hospitalized within the past 6 months whereas $16 \%$ of non-anemics were hospitalized. ${ }^{24}$ Using data from a national network of nursing homes, Robinson and colleagues reported that of the 6,200 records examined, $60 \%$ of older nursing home residents had anemia and that $43 \%$ had chronic kidney disease. ${ }^{25}$ Finally, Landi and colleagues reported that 63\% (235/372) of older residents in a single nursing home in Rome, Italy had anemia and showed that the 2-year risk of death adjusting for age and sex was $60 \%$ higher in anemic than in non-anemic residents. ${ }^{26}$ Both the high prevalence of anemia and relatively high short-term mortality rate observed by Landi et al suggests that the incidence of anemia in nursing homes (either upon admission or through the course of stay) is high and/or recovery from anemia is high, the latter of which seems doubtful. As with community-based studies, the wide range of prevalence estimates of anemia in nursing homes (48-63\%) likely reflects differences in the demographic and health status composition of residents across studies, but clearly there is a very high prevalence of anemia in nursing homes that requires further investigation.

\section{Incidence of anemia}

A major limitation of the epidemiologic literature on anemia is that the dynamics of onset and recovery are not well characterized. While there are some informal estimates based on medical practice, none of the major cohort studies of older adults listed in Table 1 are able to sufficiently address this because serial blood counts were not collected in short time intervals $(<1$ year). However, in an elegant application of epidemiologic methods to medical record data, Anía and colleagues estimated the incidence of anemia in 1986 among older residents of Olmstead County, Minnesota. ${ }^{27}$ After correcting for prevalence of anemia in the community, ${ }^{14}$ the ageand sex-adjusted incidence of WHO-defined anemia was 77.5 per 1,000 person-years. Incidence rates were higher in older men than in older women and increased with advancing age. Nearly $80 \%$ of patients with anemia subsequently had a lower hemoglobin concentration during the course of follow-up, but by 1-year of follow-up 71\% had at least one laboratory assessment with normal hemoglobin concentration. Survival was significantly poorer for the anemic patients as there was $80 \%$ more deaths that occurred over the follow-up period than would be expected given the patients' age and sex. ${ }^{27}$ In another study, Ferrucci and colleagues reported that $8 \%$ of non-anemic older adults subsequently went on to develop anemia at 3-year follow-up and showed that low levels of total and bioavailable testosterone significantly predicted anemia onset. ${ }^{28}$ A similar 3-year estimate of $7 \%$ was observed in a relatively small 
cohort study of older Koreans. ${ }^{29}$ Most recently, a study of ambulatory patients with chronic heart failure showed that the 6-month incidence of new anemia was $16 \%$ and that $43 \%$ of patients with anemia at baseline had recovered by 6 month follow-up. ${ }^{30}$ Relative to patients who were consistently non-anemic, mortality risk was significantly increased in those with persistent anemia and in those with new onset of anemia, but there was no difference in survival in patients whose anemia had resolved. ${ }^{30}$ These studies suggest that anemia is highly dynamic in older adults, but more research is needed to better characterize predictors of anemia onset, duration, and resolution.

\section{Types of Anemia}

The high burden of comorbidity and accompanying polypharmacy among older adults make it difficult to determine the underlying cause of anemia in this population. In the NHANES III, for instance, approximately two thirds of participants with anemia had 2 or more age-associated diseases. ${ }^{10}$ Nonetheless, anemia in older persons is generally subdivided into 4 major types according to cause: anemia related to nutrient deficiencies, chronic kidney disease, chronic disease or inflammation, and unexplained anemia. While each type of anemia is reviewed separately in this issue of the Journal, the distribution as observed in NHANES III and general epidemiologic concerns will be briefly reviewed in this section.

\section{Nutrient deficiency-related anemia}

Approximately one third of anemia cases in older adults are attributed to iron, folate, and/or vitamin $\mathrm{B}_{12}$ deficiencies (Table 2). ${ }^{10}$ Iron deficiency alone accounts for nearly half of the nutrient deficiency-related anemia cases. While some cases of iron deficiency results from diet, 31 blood loss through gastrointestinal lesions is the primary cause in older adults. ${ }^{32-34}$ For example, gastrointestinal endoscopy in 100 consecutive patients with iron deficiency anemia showed that $62 \%$ had a lesion that could potentiate blood loss and $16 \%$ had premalignant polyps or colon cancer. ${ }^{33}$ However, diagnosing iron deficiency in older adults is difficult because serum ferritin concentration, a key test of iron storage, is known to increase with age and ageassociated diseases. ${ }^{35,} 36$ Indeed, a study of hospitalized patients age 80 years and older showed that the routine blood tests of serum iron, ferritin, and transferrin saturation had poor screening sensitivity for capturing iron deficient patients. ${ }^{37}$ Considering that the more sensitive transferrin receptor-ferritin index or ratio has only recently become more widely-available, prevalence of iron deficiency anemia based on the routine blood tests among older adults might be underestimated in NHANES III, ${ }^{10}$ although a recent representative study of older adults used the transferrin receptor-ferritin index and showed that $16.7 \%$ of anemia cases were attributed to iron deficiency anemia (similar to the $16.6 \%$ estimate from NHANES III shown in Table 2). ${ }^{38}$

Folate and vitamin $\mathrm{B}_{12}$ deficiencies are also common among community-dwelling older adults and minimally account for $14 \%$ of all anemia cases (Table 2). The classification of vitamin $\mathrm{B}_{12}$ deficiency was based on serum concentration in the NHANES III, ${ }^{10}$ which does not adequately detect subclinical cases of vitamin $B_{12}$ deficiency. ${ }^{39-41}$ If methylmalonic acid testing had been performed in NHANES III, then this information in conjunction with homocysteine concentration would have helped to capture more cases of mild vitamin $\mathrm{B}_{12}$ deficiency and therefore the prevalence of anemia related to vitamin $B_{12}$ deficiency would be slightly higher than the estimates shown in Table $2 .{ }^{42}$ (See the article by Dr. Carmel in this issue of the Journal for a complete review of cobalamin deficiency).

\section{Anemia of chronic disease or inflammation}

In addition to nutrient deficiency, chronic immune activation and inflammation that result from infection or chronic conditions can cause anemia. ${ }^{43}$ It is not surprising then that nearly a fifth of anemia cases (19.7\%) in older adults were classified as anemia of chronic inflammation, 
which was formerly called anemia of chronic disease (Table 2). ${ }^{10}$ However, distinguishing anemia of chronic inflammation from iron deficiency anemia is particularly challenging in older adults because of the comorbid effects of gastrointestinal bleeding as well as the effects of medications. ${ }^{43}$ It is likely that the prevalence of anemia of chronic inflammation alone is overestimated in the NHANES III at the expense of iron deficiency anemia because serum ferritin levels can be normal when both types of anemia are present. Indeed, even distinguishing anemia of chronic inflammation from anemia of chronic kidney disease is somewhat tenuous given the emerging evidence that there is increased inflammation associated with renal function in older adults without chronic kidney disease. ${ }^{44}$ Considering the tremendous extent of subclinical and clinical morbidities among older adults as well as increased levels of proinflammatory cytokines that accompany aging, identifying the putative factor underlying anemia of chronic inflammation in older adults is very difficult.

\section{Anemia of chronic kidney disease}

Chronic kidney disease can impair the production of erythropoietin and therefore it is an important cause of anemia. In NHANES III, $8 \%$ of older participants with anemia had renal insufficiency with creatinine clearance below $30 \mathrm{~mL} / \mathrm{min}$ and another $4 \%$ of anemia cases had both renal insufficiency and anemia of chronic inflammation. ${ }^{10}$ However, only a few studies have characterized the relationship between renal function and anemia among older adults. Generally, these studies indicate that there is a renal function threshold below which the risk of anemia increases, but the threshold value varies between studies, ranging from $30 \mathrm{~mL} / \mathrm{min}$ to $60 \mathrm{~mL} / \mathrm{min} .^{45-48}$ The problem is compounded by use of different equations to estimate glomerular filtration rate as well as different serum creatinine assays. It is likely, though, that the prevalence of anemia of chronic kidney disease in older adults is higher than shown in Table 2.

\section{Unexplained anemia}

One third of older adults with anemia in the NHANES III did not meet the criteria of having anemia related to nutrient deficiency, chronic inflammation, or chronic kidney disease and therefore were classified as "unexplained anemia". ${ }^{10}$ Importantly, other groups have also reported that approximately one-third of anemia cases were unexplained in different samples of older adults. ${ }^{38,49}$ However, it is likely that some proportion of unexplained anemia cases are caused by myelodysplastic syndrome (MDS), another common hematologic condition in older adults. ${ }^{50}$ Guralnik et al. liberally estimated that up to $17.2 \%$ of unexplained anemia cases (5.8\% of all anemia cases) may be attributed to MDS by examining the co-occurrence of neutropenia, thrombocytopenia, or macrocytosis with unexplained anemia. ${ }^{10}$ Nonetheless, a substantial proportion of anemia cases (approximately 25\%) would remain unexplained even after accounting for MDS. ${ }^{10}$ (See the article by Dr. Ershler in this issue of the Journal for a complete review of unexplained anemia).

\section{Association of Anemia with Mortality}

Several large cohort studies have demonstrated that WHO-defined anemia is associated with increased risk of death among older adults. ${ }^{5-9}$ Associations were robust to extensive adjustment for potential confounding factors, with adjusted hazard ratios comparing anemic to non-anemic older adults ranging from 1.4 to 2.7. Three studies even showed that the effect of anemia on survival remained significant even after excluding participants with major ageassociated conditions. ${ }^{6-8}$ Most studies observed a reversed J-shape association between hemoglobin levels and mortality with risk increasing as a function of anemia severity. The higher mortality associated with higher hemoglobin levels might reflect unmeasured pulmonary disease and/or inadequate adjustment for smoking history. Some investigators have also reported that low normal hemoglobin values, such as $0-0.9 \mathrm{~g} / \mathrm{dL}$ above the WHO cutoffs, 
were associated with increased risk of death in older adults. $3,4,8,9$ For example, Culleton and colleagues showed that older women with hemoglobin concentration $12.0-12.9 \mathrm{~g} / \mathrm{dL}$ were significantly more likely to die compared to those with hemoglobin 13.0-13.9 g/dL adjusting for multiple potential confounders, although the same comparison in men did not reach statistical significance (Figure 4). ${ }^{4}$ That low normal hemoglobin levels have adverse consequences has motivated reconsideration of the hemoglobin cutpoints for defining anemia in older adults. However, it is important to note that some studies did not find low normal hemoglobin values were associated with increased risk of death. ${ }^{5,7} \mathrm{~A}$ variety of factors can contribute to differences in results across studies, including study sample demographics, disease burden, hemoglobin cutpoints, sample size in hemoglobin categories, length of followup, and the reference category used to make comparisons. Future prospective studies evaluating the risk for adverse events according to hemoglobin concentration should consider using spline models or other statistical methods to best characterize the curvilinear relationship and identify thresholds of risk. Such an approach was effectively taken by Chaves and colleagues to demonstrate that mortality decreased steadily until a hemoglobin threshold of $13.9 \mathrm{~g} / \mathrm{dL}$ in older disabled women ${ }^{3}$ however, in addition to reporting the inflection point where mortality risk is lowest, it would also be useful to report the hemoglobin threshold below which mortality risk is significantly increased. This type of approach will help overcome some of the impediments to comparing results across studies and will help determine whether separate hemoglobin thresholds are warranted in different demographic subgroups.

\section{Conclusions}

Anemia is a common, multifactorial condition among older adults that is associated with a variety of adverse outcomes, including mortality. While the epidemiology of anemia has advanced considerably in recent years, further investigation of several areas is needed. More outcomes-based research should be pursued to help define the hemoglobin threshold at which anemia occurs by race and sex. A larger effort is needed to better characterize the dynamics of anemia onset, chronicity, and recovery. Such investigation could also enable determination of whether persistent anemia or new onset of anemia increases risk for adverse events in older adults. Additionally, the level of renal function at which erythropoietin response to anemia is reduced remains unclear. Finally, the comorbid effects of anemia on cognitive and physical function as well as on other outcomes, including hospital and nursing home admission, merit more attention. Addressing these epidemiologic aspects of anemia will not only inform geriatric care but will also provide valuable information for the planning and conduct of future randomized controlled trials on anemia in older adults, which would ultimately help determine whether anemia is a marker of disease burden or is itself on the causal pathway to disability and death.

\section{Acknowledgments}

This study was supported by the Intramural Research Program of the US National Institute on Aging, National Institutes of Health.

\section{References}

1. United Nations Department of Economic and Social Affairs. Population Division: World Population Prospects. The 2006 Revision. New York: United Nations; 2007.

2. Federal Interagency Forum on Aging-Related Statistics. Older Americans Update 2008: Key Indicators of Well-Being. Washington, DC: US Government Printing Office; 2008.

3. Chaves PH, Xue QL, Guralnik JM, Ferrucci L, Volpato S, Fried LP. What constitutes normal hemoglobin concentration in community-dwelling disabled older women? J Am Geriatr Soc 2004;52:1811-1816. [PubMed: 15507056] 
4. Culleton BF, Manns BJ, Zhang J, Tonelli M, Klarenbach S, Hemmelgarn BR. Impact of anemia on hospitalization and mortality in older adults. Blood 2006;107:3841-3846. [PubMed: 16403909]

5. Denny SD, Kuchibhatla MN, Cohen HJ. Impact of anemia on mortality, cognition, and function in community-dwelling elderly. Am J Med 2006;119:327-334. [PubMed: 16564775]

6. Izaks GJ, Westendorp RG, Knook DL. The definition of anemia in older persons. JAMA 1999;281:1714-1717. [PubMed: 10328071]

7. Patel KV, Harris TB, Faulhaber M, Angleman SB, Connelly J, Bauer DC, et al. Racial variation in the relationship of anemia with mortality and mobility disability among older adults. Blood 2007;109:4663-4670. [PubMed: 17284526]

8. Penninx BW, Pahor M, Woodman RC, Guralnik JM. Anemia in old age is associated with increased mortality and hospitalization. J Gerontol A Biol Sci Med Sci 2006;61:474-479. [PubMed: 16720744]

9. Zakai NA, Katz R, Hirsch C, Shlipak MG, Chaves PH, Newman AB, et al. A prospective study of anemia status, hemoglobin concentration, and mortality in an elderly cohort: the Cardiovascular Health Study. Arch Intern Med 2005;165:2214-2220. [PubMed: 16246985]

10. Guralnik JM, Eisenstaedt RS, Ferrucci L, Klein HG, Woodman RC. Prevalence of anemia in persons 65 years and older in the United States: evidence for a high rate of unexplained anemia. Blood 2004;104:2263-2268. [PubMed: 15238427]

11. Inelmen EM, D'Alessio M, Gatto MR, BAggio MB, Jimenez G, Bizzotto MG, et al. Descriptive analysis of the prevalence of anemia in a randomly selected sample of elderly people living at home: some results of an Italian multicentric study. Aging (Milano) 1994;6:81-89. [PubMed: 7918735]

12. Penninx BW, Pahor M, Cesari M, Corsi AM, Woodman RC, Bandinelli S, et al. Anemia is associated with disability and decreased physical performance and muscle strength in the elderly. $\mathrm{J}$ Am Geriatr Soc 2004;52:719-724. [PubMed: 15086651]

13. Salive ME, Cornoni-Huntley J, Guralnik JM, Phillips CL, Wallace RB, Ostfeld AM, et al. Anemia and hemoglobin levels in older persons: relationship with age, gender, and health status. J Am Geriatr Soc 1992;40:489-496. [PubMed: 1634703]

14. Ania BJ, Suman VJ, Fairbanks VF, Melton LJ 3rd. Prevalence of anemia in medical practice: community versus referral patients. Mayo Clin Proc 1994;69:730-735. [PubMed: 8035626]

15. Skjelbakken T, Langbakk B, Dahl IM, Lochen ML. Haemoglobin and anaemia in a gender perspective: the Tromso Study. Eur J Haematol 2005;74:381-388. [PubMed: 15813911]

16. Perry GS, Byers T, Yip R, Margen S. Iron nutrition does not account for the hemoglobin differences between blacks and whites. J Nutr 1992;122:1417-1424. [PubMed: 1619469]

17. Johnson-Spear MA, Yip R. Hemoglobin difference between black and white women with comparable iron status: justification for race-specific anemia criteria. Am J Clin Nutr 1994;60:117-121. [PubMed: 8017324]

18. Beutler E, Waalen J. The definition of anemia: what is the lower limit of normal of the blood hemoglobin concentration? Blood 2006;107:1747-1750. [PubMed: 16189263]

19. Robins EB, Blum S. Hematologic reference values for African American children and adolescents. Am J Hematol 2007;82:611-614. [PubMed: 17177189]

20. Beutler E, West C. Hematologic differences between African-Americans and whites: the roles of iron deficiency and alpha-thalassemia on hemoglobin levels and mean corpuscular volume. Blood 2005;106:740-745. [PubMed: 15790781]

21. International Nutritional Anemia Consultative Group. Adjusting hemoglobin values in program surveys. Washington, DC: ILSI Human Nutrition Institute; 2002.

22. Earl, R.; Woteki, CE., editors. Food and Nutrition Board, Institute of Medicine. Washington, DC: National Academy Press; 1993. Iron deficiency anemia: recommended guidelines for the prevention, detection, and management among US children and women of childbearing age.

23. WHO/UNICEF/UNU. Iron deficiency anemia, assessment, prevention and control: a guide for programme managers. WHO/NHD/01.3. Geneva: WHO; 2001.

24. Artz AS, Fergusson D, Drinka PJ, Gerald M, Gravenstein S, Lechich A, et al. Prevalence of anemia in skilled-nursing home residents. Arch Gerontol Geriatr 2004;39:201-206. [PubMed: 15381339]

25. Robinson B, Artz AS, Culleton B, Critchlow C, Sciarra A, Audhya P. Prevalence of anemia in the nursing home: contribution of chronic kidney disease. J Am Geriatr Soc 2007;55:1566-1570. [PubMed: 17727646] 
26. Landi F, Russo A, Danese P, Liperoti R, Barillaro C, Bernabei R, et al. Anemia status, hemoglobin concentration, and mortality in nursing home older residents. J Am Med Dir Assoc 2007;8:322-327. [PubMed: 17570312]

27. Ania BJ, Suman VJ, Fairbanks VF, Rademacher DM, Melton LJ 3rd. Incidence of anemia in older people: an epidemiologic study in a well defined population. J Am Geriatr Soc 1997;45:825-831. [PubMed: 9215333]

28. Ferrucci L, Maggio M, Bandinelli S, Basaria S, Lauretani F, Ble A, et al. Low testosterone levels and the risk of anemia in older men and women. Arch Intern Med 2006;166:1380-1388. [PubMed: 16832003]

29. Choi CW, Lee J, Park KH, Choi IK, Kim SJ, Seo JH, et al. Incidence of anemia in older Koreans: community-based cohort study. Arch Gerontol Geriatr 2005;41:303-309. [PubMed: 15964084]

30. Tang WH, Tong W, Jain A, Francis GS, Harris CM, Young JB. Evaluation and long-term prognosis of new-onset, transient, and persistent anemia in ambulatory patients with chronic heart failure. $\mathrm{J} \mathrm{Am}$ Coll Cardiol 2008;51:569-576. [PubMed: 18237687]

31. Drewnowski A, Shultz JM. Impact of aging on eating behaviors, food choices, nutrition, and health status. J Ntrn Health Aging 2001;5:75-79.

32. Coban E, Timuragaoglu A, Meric M. Iron deficiency anemia in the elderly: prevalence and endoscopic evaluation of the gastrointestinal tract in outpatients. Acta Haematol 2003;110:25-28. [PubMed: 12975553]

33. Rockey DC, Cello JP. Evaluation of the gastrointestinal tract in patients with iron-deficiency anemia. N Engl J Med 1993;329:1691-1695. [PubMed: 8179652]

34. Joosten E, Ghesquiere B, Linthoudt H, Krekelberghs F, Dejaeger E, Boonen S, et al. Upper and lower gastrointestinal evaluation of elderly inpatients who are iron deficient. Am J Med 1999;107:24-29. [PubMed: 10403349]

35. Casale G, Bonora C, Migliavacca A, Zurita IE, de Nicola P. Serum ferritin and ageing. Age Ageing 1981;10:119-122. [PubMed: 7246336]

36. Witte DL. Can serum ferritin be effectively interpreted in the presence of the acute-phase response? Clin Chem 1991;37:484-485. [PubMed: 1901771]

37. Rimon E, Levy S, Sapir A, Gelzer G, Peled R, Ergas D, et al. Diagnosis of iron deficiency anemia in the elderly by transferrin receptor-ferritin index. Arch Intern Med 2002;162:445-449. [PubMed: 11863478]

38. Ferrucci L, Guralnik JM, Bandinelli S, Semba RD, Lauretani F, Corsi A, et al. Unexplained anaemia in older persons is characterised by low erythropoietin and low levels of pro-inflammatory markers. Br J Haematol 2007;136:849-855. [PubMed: 17341272]

39. Balducci L. Epidemiology of anemia in the elderly: information on diagnostic evaluation. J Am Geriatr Soc 2003;51:S2-S9. [PubMed: 12588565]

40. Carmel R, Green R, Rosenblatt DS, Watkins D. Update on cobalamin, folate, and homocysteine. Hematology Am Soc Hematol Educ Program 2003:62-81. [PubMed: 14633777]

41. Savage DG, Lindenbaum J, Stabler SP, Allen RH. Sensitivity of serum methylmalonic acid and total homocysteine determinations for diagnosing cobalamin and folate deficiencies. Am J Med 1994;96:239-246. [PubMed: 8154512]

42. Stabler SP, Lindenbaum J, Allen RH. The use of homocysteine and other metabolites in the specific diagnosis of vitamin B-12 deficiency. J Nutr 1996;126:1266S-1272S. [PubMed: 8642468]

43. Weiss G, Goodnough LT. Anemia of chronic disease. N Engl J Med 2005;352:1011-1023. [PubMed: 15758012]

44. Keller CR, Odden MC, Fried LF, Newman AB, Angleman S, Green CA, et al. Kidney function and markers of inflammation in elderly persons without chronic kidney disease: the health, aging, and body composition study. Kidney Int 2007;71:239-244. [PubMed: 17183246]

45. Astor BC, Muntner P, Levin A, Eustace JA, Coresh J. Association of kidney function with anemia: the Third National Health and Nutrition Examination Survey (1988-1994). Arch Intern Med 2002;162:1401-1408. [PubMed: 12076240]

46. Ble A, Fink JC, Woodman RC, Klausner MA, Windham BG, Guralnik JM, et al. Renal function, erythropoietin, and anemia of older persons: the InCHIANTI study. Arch Intern Med 2005; 165:22222227. [PubMed: 16246987] 
47. Cumming RG, Mitchell P, Craig JC, Knight JF. Renal impairment and anaemia in a population-based study of older people. Intern Med J 2004;34:20-23. [PubMed: 14748909]

48. Hsu CY, McCulloch CE, Curhan GC. Epidemiology of anemia associated with chronic renal insufficiency among adults in the United States: results from the Third National Health and Nutrition Examination Survey. J Am Soc Nephrol 2002;13:504-510. [PubMed: 11805181]

49. Artz AS, Fergusson D, Drinka PJ, Gerald M, Bidenbender R, Lechich A, et al. Mechanisms of unexplained anemia in the nursing home. J Am Geriatr Soc 2004;52:423-427. [PubMed: 14962159]

50. Strom SS, Velez-Bravo V, Estey EH. Epidemiology of myelodysplastic syndromes. Sem Hematol 2008;45:8-13. 


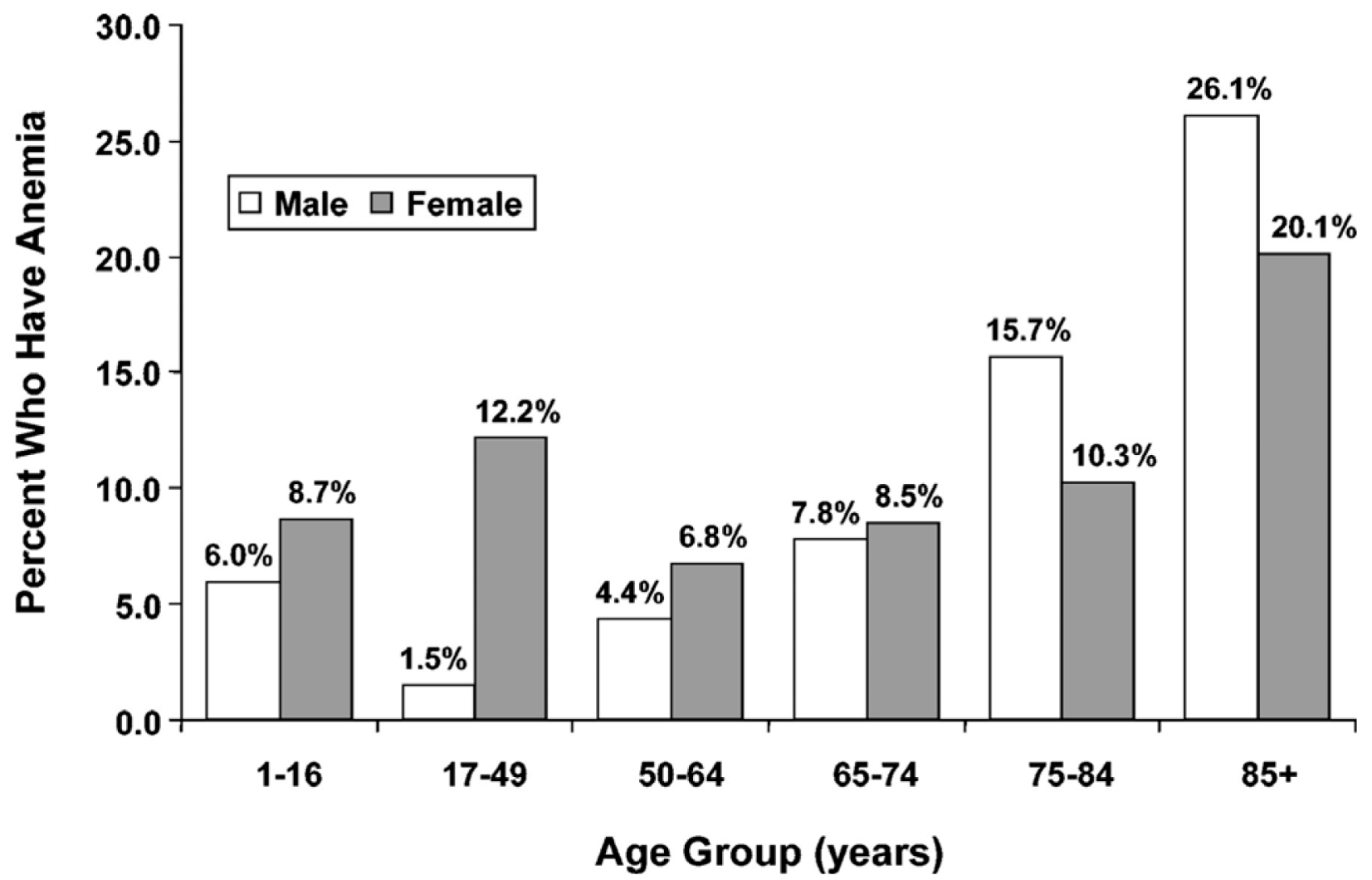

Figure 1. Percent of persons anemic according to age and sex* NHANES III, Phases I and II, 1988-94.

*Note: This research was originally published in Blood. Guralnik JM, Eisenstaedt RS, Ferrucci L, Klein HG, Woodman RC. Prevalence of anemia in persons 65 years and older in the United States: evidence for a high rate of unexplained anemia. Blood. 2004;104:2263-2268. (C) The American Society of Hematology. 10 


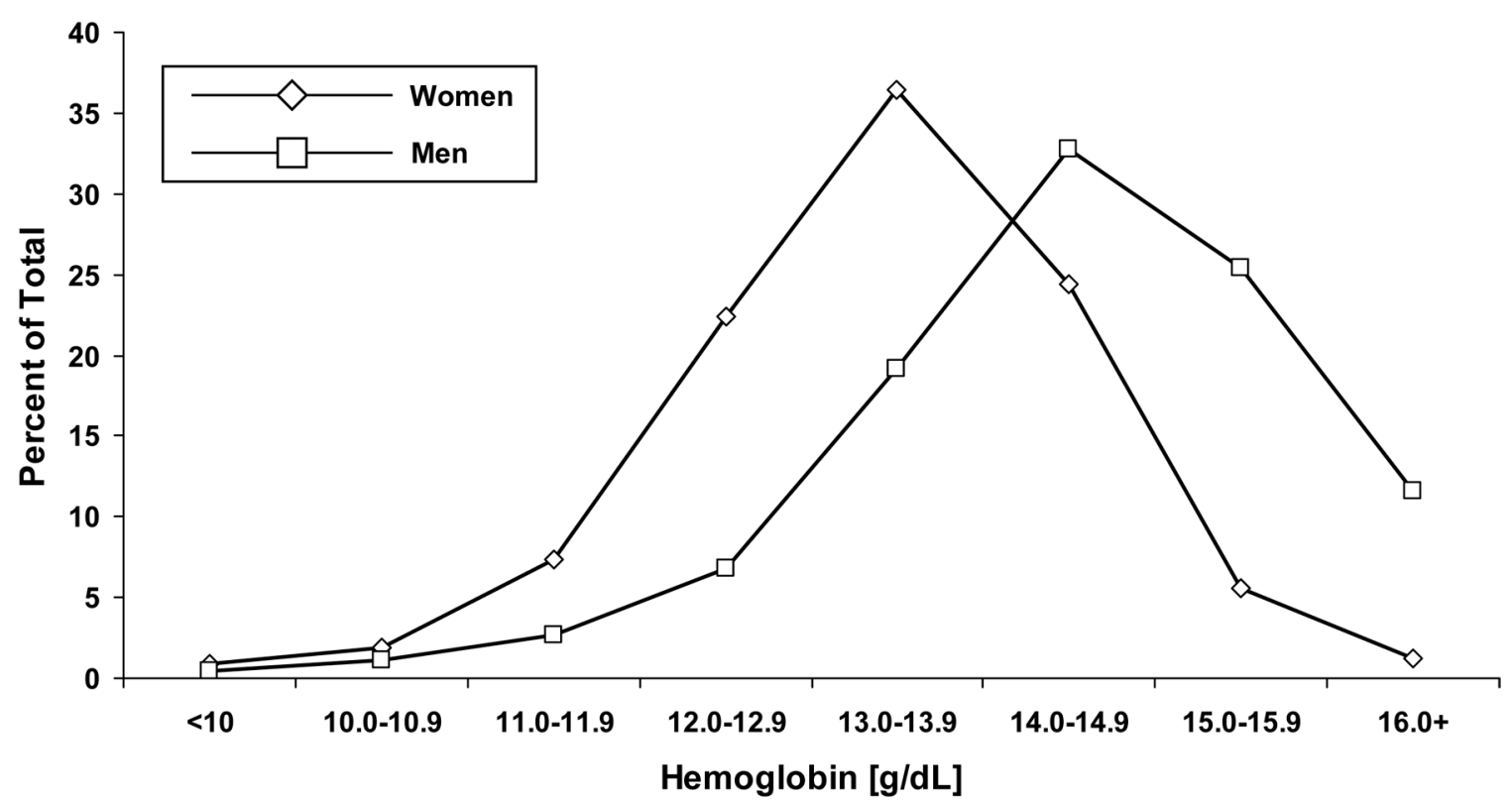

Figure 2. Distribution of hemoglobin in persons 65 years and older according to sex* NHANES III, Phases I and II, 1988 to 1994

*Note: This research was originally published in Blood. Guralnik JM, Eisenstaedt RS, Ferrucci L, Klein HG, Woodman RC. Prevalence of anemia in persons 65 years and older in the United States: evidence for a high rate of unexplained anemia. Blood. 2004;104:2263-2268. (C) The American Society of Hematology. ${ }^{10}$ 


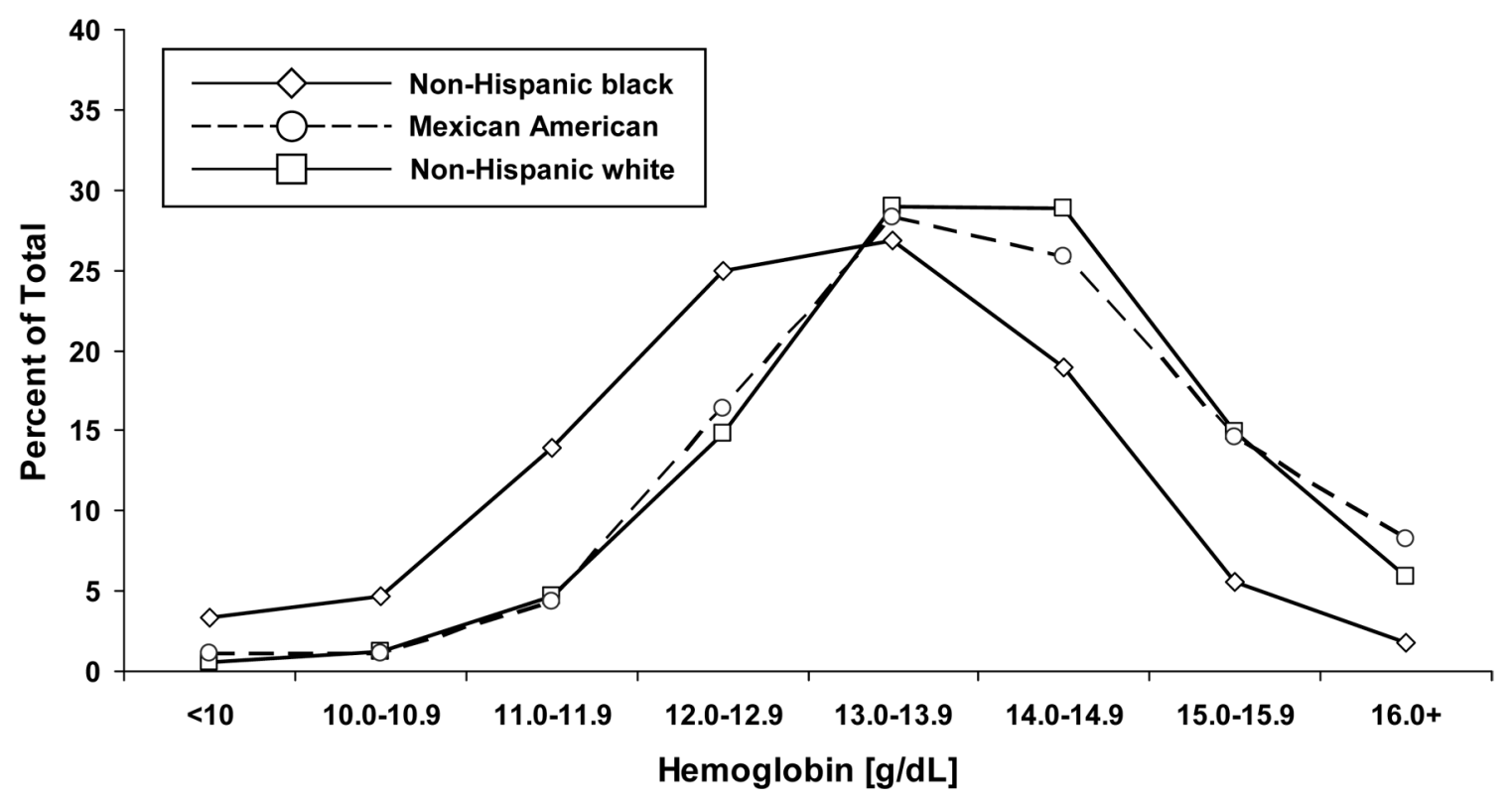

Figure 3. Distribution of hemoglobin in persons 65 years and older according to race/ethnicity* NHANES III, Phases I and II, 1988 to 1994

*Note: Author's analysis of NHANES III data. 

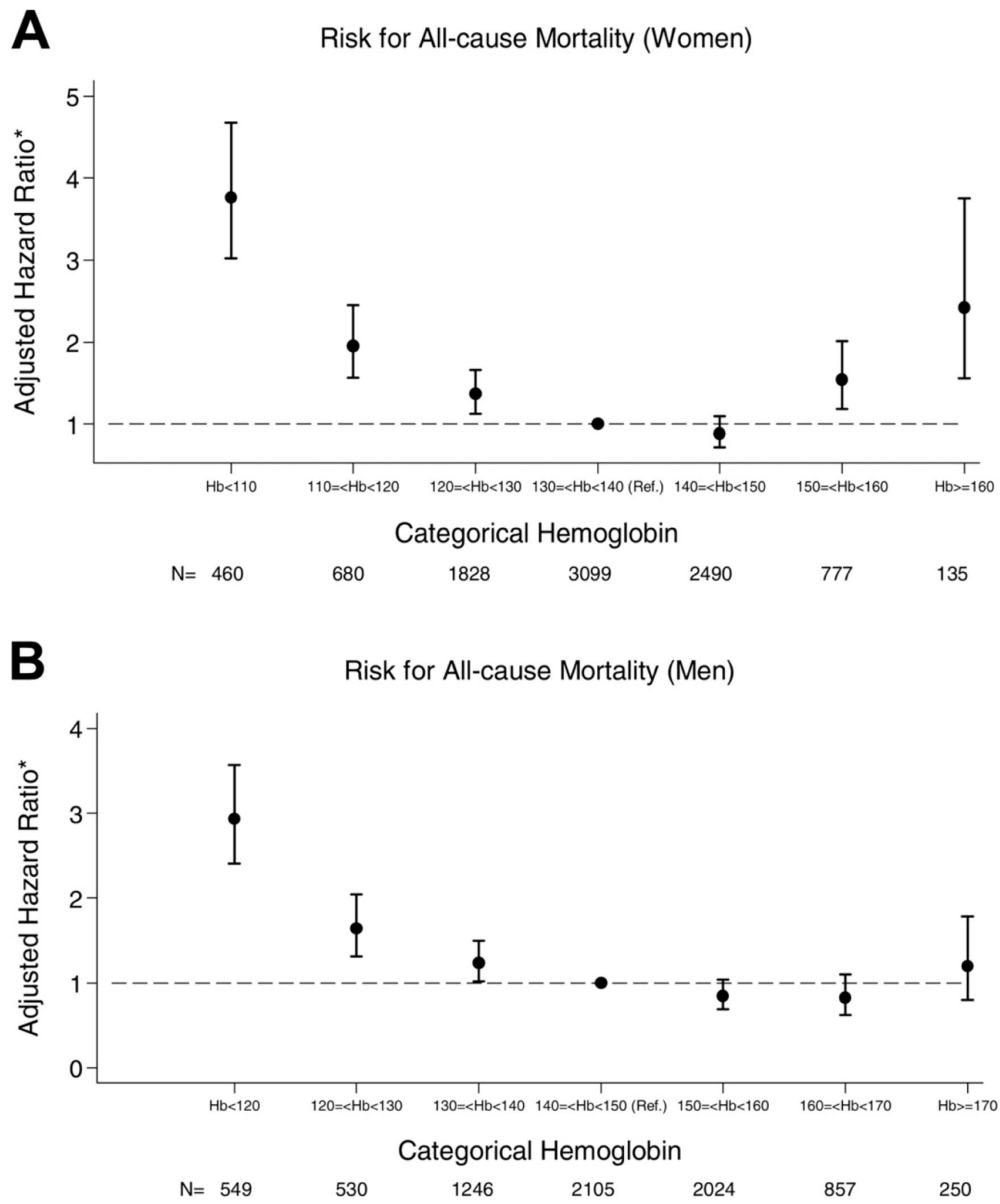

Figure 4. Association between hemoglobin and risk for all-cause mortality**

(A) Women. (B) Men. Each $\bullet$ indicates a point estimate for this risk, and the vertical lines represent $95 \%$ confidence intervals around these estimates. *Adjusted for age, diabetes mellitus, GFR, and comorbidity

**Note: This research was originally published in Blood. Culleton BF, Manns BJ, Zhang J, Tonelli M, Klarenbach S, Hemmelgarn BR. Impact of anemia on hospitalization and mortality in older adults. Blood. 2006;107:3841-3846. (C) The American Society of Hematology. ${ }^{4}$ 


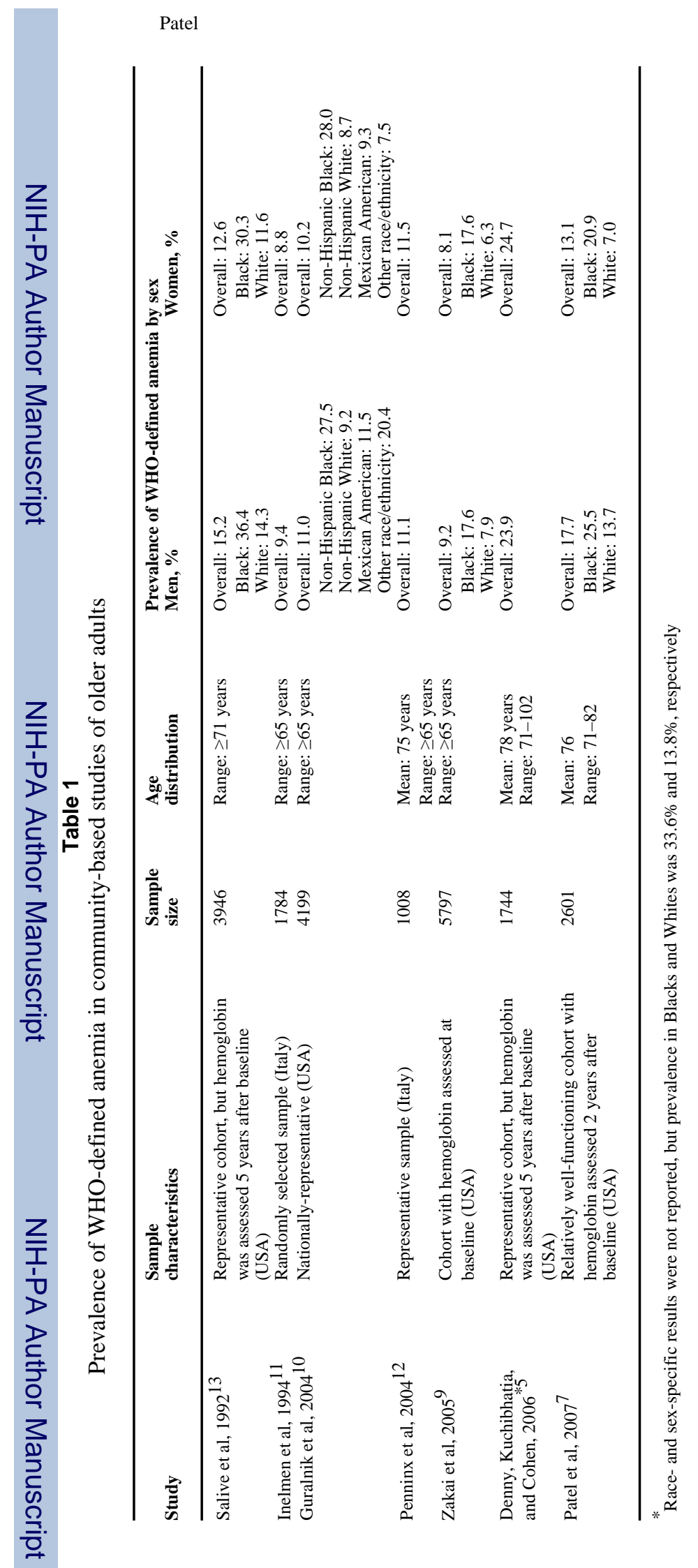

Page 15 
Table 2

Distribution of Types of Anemia in Persons Age 65 and Older, U.S.*

NHANES III, Phase II, 1991-94.

\begin{tabular}{|c|c|c|c|}
\hline Anemia & $\begin{array}{l}\text { Number in the } \\
\text { United States }\end{array}$ & Type, \% & All anemia, \% \\
\hline \multicolumn{4}{|l|}{ With nutrient deficiency } \\
\hline Iron only & 466,715 & 48.3 & 16.6 \\
\hline Folate only & 181,471 & 18.8 & 6.4 \\
\hline $\mathrm{B}_{12}$ only & 165,701 & 17.2 & 5.9 \\
\hline Folate and $\mathrm{B}_{12}$ & 56,436 & 5.8 & 2.0 \\
\hline Iron with folate or $\mathrm{B}_{12}$ or both & 95,221 & 9.9 & 3.4 \\
\hline Total & 965,544 & 100.0 & 34.3 \\
\hline \multicolumn{4}{|l|}{ Without nutrient deficiencies } \\
\hline Renal insufficiency only & 229,686 & 12.4 & 8.2 \\
\hline ACI, no renal insufficiency & 554,281 & 30.0 & 19.7 \\
\hline Renal insufficiency and ACI & 120,169 & 6.5 & 4.3 \\
\hline Unexplained anemia & 945,195 & 51.1 & 33.6 \\
\hline Total & $1,849,331$ & 100.0 & 65.7 \\
\hline Total, all anemia & $2,814,000$ & NA & \\
\hline
\end{tabular}

ACI indicates anemia of chronic inflammation and NA indicates not applicable

*

Note: This research was originally published in Blood. Guralnik JM, Eisenstaedt RS, Ferrucci L, Klein HG, Woodman RC. Prevalence of anemia in persons 65 years and older in the United States: evidence for a high rate of unexplained anemia. Blood. 2004;104:2263-2268. (C) The American Society of Hematology. 10 